\title{
Tribological Characteristics of the Magnesium Matrix-Glassy Carbon Particles Composite Manufactured by Different Casting Methods
}

\author{
Anita Olszówka-Myalska, Jerzy Myalski, and Bartosz Hekner \\ Institute of Materials Science, Faculty of Materials Science and Metallurgy, Silesian University of Technology, \\ Ulica Krasińskiego 8, 40-019 Katowice, Poland
}

Correspondence should be addressed to Anita Olszówka-Myalska; anita.olszowka-myalska@polsl.pl

Received 5 July 2014; Accepted 2 December 2014

Academic Editor: Martin Dienwiebel

This Conference Paper is based on a presentation given by Bartosz Hekner at "European Symposium on Friction, Wear, and Wear Protection" held from 6 May 2014 to 8 May 2014 in Karlsruhe, Germany.

Copyright (C) 2015 Anita Olszówka-Myalska et al. This is an open access article distributed under the Creative Commons Attribution License, which permits unrestricted use, distribution, and reproduction in any medium, provided the original work is properly cited.

\begin{abstract}
A particulate composite with a magnesium matrix (Mg3Al) and glassy carbon particles (GCp) obtained under industrial conditions from a gravity cast and pressure die cast suspension was examined. The influence of the casting procedure on the microstructure and mechanical properties was revealed. Sliding friction tests by the pin-on-disc method for different loads $(2.3,5$, and 9.3 N) and speeds $(0.06,0.09$, and $0.14 \mathrm{~m} / \mathrm{s})$ were performed. Regardless of the technology, the sliding friction coefficient's value strongly depended on the load and speed. Its value was changing (0.35-0.13) and was usually higher for the pressure die cast material, yet the wear resistance of the composite processed in that way was considerably better compared with the gravity cast. The results of the worn surface observation by SEM with EDS showed an influence of the initial Mg3Al-GCp composite's microstructure on the processes of its wear.
\end{abstract}

\section{Introduction}

The application of glassy carbon particles $[1,2]$ as a component of a metal matrix composite can be a way of modifying the tribological properties of metal-based materials [3-5] and it is proposed for composites with matrixes made of aluminium and magnesium alloys. However, the properties of the new materials designed and obtained under precisely controlled conditions in the laboratory scale must be verified in the case when they are manufactured in the industrial scale. This is due to the fact that the processing of semifinished and finished composite products of a proper size and shape is more complex, and many additional factors influence the final microstructure and properties [5].

The subject of the presented research was a magnesium matrix composite $(\mathrm{Mg} 3 \mathrm{Al})$ with the particles of glassy carbon (GCp) which was manufactured from a metal-particle suspension by means of two different casting procedures under industrial conditions. For the first case a suspension was gravity cast just after the mechanical mixing of the components, and the semi-product ingots were examined. In the alternative technology, the gravity cast ingots of the same Mg3Al-GCp composite were remelted, and pressure die cast elements were obtained. The influence of the technology on the microstructure and properties, including the sliding friction wear, was analyzed.

\section{Material and Methods}

The composite processing involved the application of a magnesium alloy with 3 weight $\%$ of $\mathrm{Al}$ and GCp of granulation less than $200 \mu \mathrm{m}$ and hardness of $260 \mathrm{HV}_{0.2}$. The glassy carbon particles were obtained by pyrolysis of organic resin and then refining by milling. After the milling process they were characterized by an irregular shape and the presence of riffles 


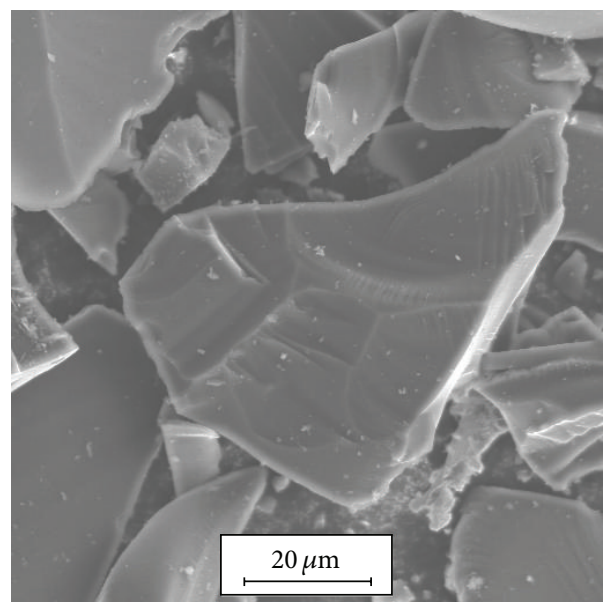

FIGURE 1: SEM micrograph of GCp, irregular shaped particles, and typical surface defects are visible.

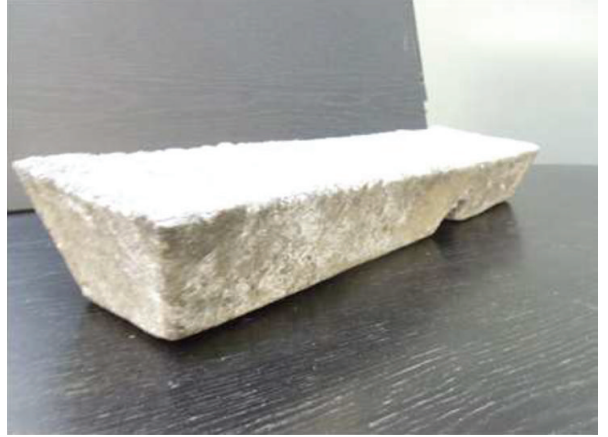

(a)

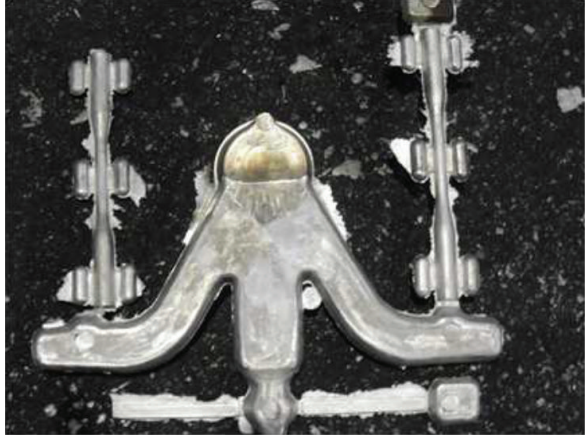

(b)

FIGURE 2: View of composite casts fabricated by gravity casting (a) and pressure die casting (b).

on their surface (Figure 1). To obtain a Mg3Al-GCp composite with 13 volume \% of particles, two different technological procedures were employed. One technology consisted of two steps: obtaining a suspension (mass approx. $35 \mathrm{~kg}$ ) by mechanical stirring of the melted alloy with heated glassy carbon particles in a protective atmosphere of an $\mathrm{Ar}$ and $\mathrm{SF}_{6}$ gas mixture and gravity casting of the suspension into a steel mould (stir casting). In the other technological variant, the ingots fabricated by gravity casting were remelted and the suspension was mixed again and then poured into a cold chamber pressure die casting machine. The temperature of the suspension in both technologies was not higher than $690^{\circ} \mathrm{C}$, as it was necessary to reduce the possibility of hydrophilic $\mathrm{Al}_{4} \mathrm{C}_{3}$ carbide formation. A view of the obtained gravity and pressure die cast products being the research material is presented in Figure 2. The hardness values of the composite were $33 \mathrm{HB}$ and $68 \mathrm{HB}$, for the gravity cast and pressure die cast material, respectively. Due to the fact that the samples for the tensile strength test manufactured by gravity casting were defected, which was a result of the poor suspension castability at the applied casting conditions, a proper measurement of their properties was impossible. In the case of the pressure die cast samples (Figure 2(b)), the mechanical properties were as follows: $R_{m}-68 \mathrm{MPa}, R_{0.2}-$ $50 \mathrm{MPa}, E-16.55 \mathrm{GPa}$, and $\varepsilon-2.3 \%$.

For the composite's microstructure characterization by the light microscopy method (LM), polished cross-sectioned and unetched samples were prepared. The composite samples fractured in the tensile strength test were characterized with the use of a scanning electron microscope (SEM Hitachi FE S4200).

The friction sliding tests were performed with a tribotester (Silesian University of Technology) under dry conditions, in ambient air, at the temperature of $20^{\circ} \mathrm{C}$ [6]. In these tests, a counter of EN-GJL300 cast iron, $3 \mathrm{~mm}$ in diameter and with the hardness of $200 \mathrm{HB}$, was loaded and oscillated on the sample's surface over a distance stroke of $9 \mathrm{~mm}$. The measurements were performed at a total distance of approximately $250 \mathrm{~m}$, under the loads of $2.3,5$, and $9.3 \mathrm{~N}$ and with the sliding speeds of $0.06,0.09$, and $0.14 \mathrm{~m} / \mathrm{s}$. The value of the friction force was measured continuously with a strain gauge (type UTILCELL model 120S) and registered with the measuring system SPIDER8, equipped with the CATMAN program. In the experiment, samples of $13 \times 13 \times 50 \mathrm{~mm}$, grounded with emery paper (grit size 500) and cleaned with ethanol, were applied. The mass of the cleaned samples and 


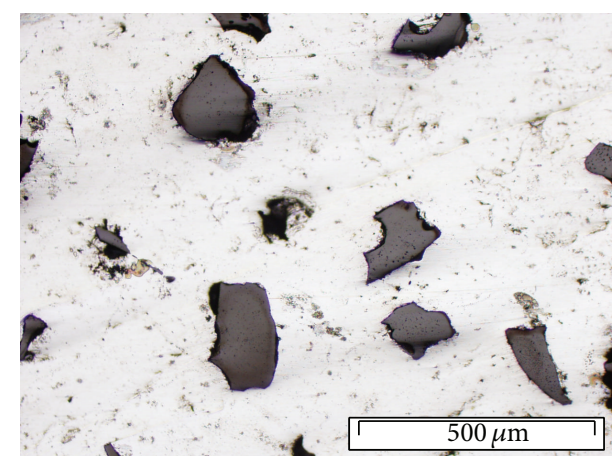

(a)

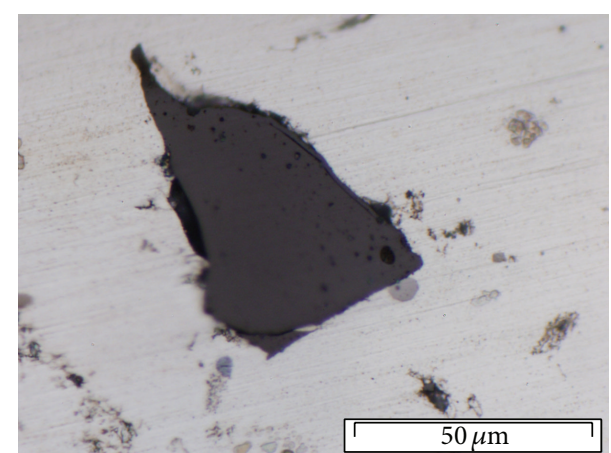

(b)

FIGURE 3: LM micrographs of gravity cast composite, polished cross section unetched, and microvoids in matrix and at interface are visible.

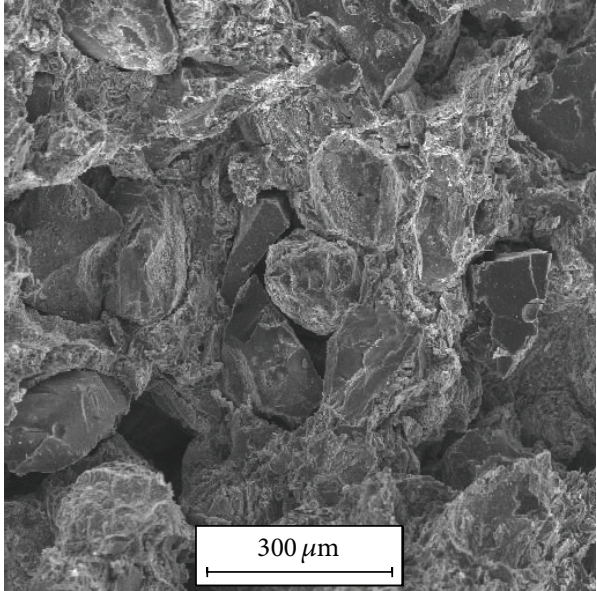

(a)

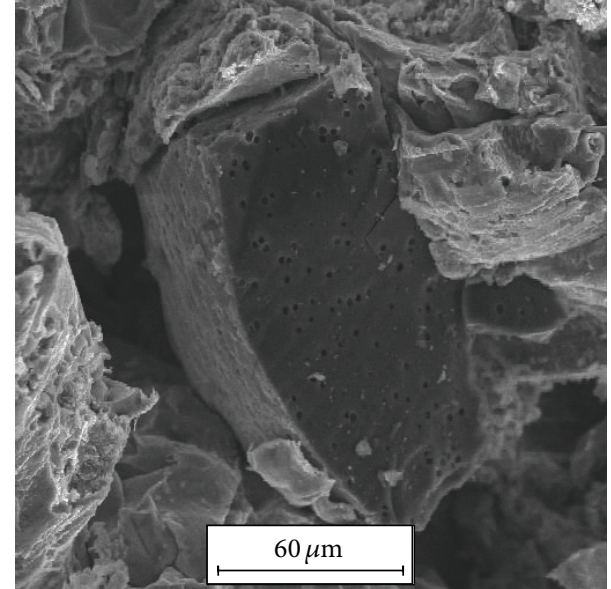

(b)

FIGURE 4: SEM micrographs of gravity cast composite, fractured cross section, particles pulled out from matrix, and microvoids in matrix and at interface are visible.

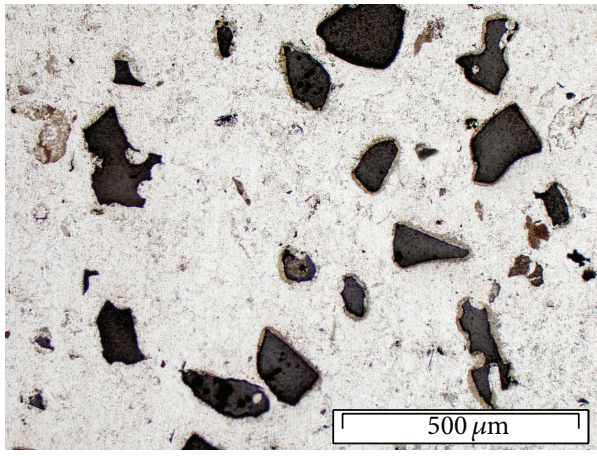

(a)

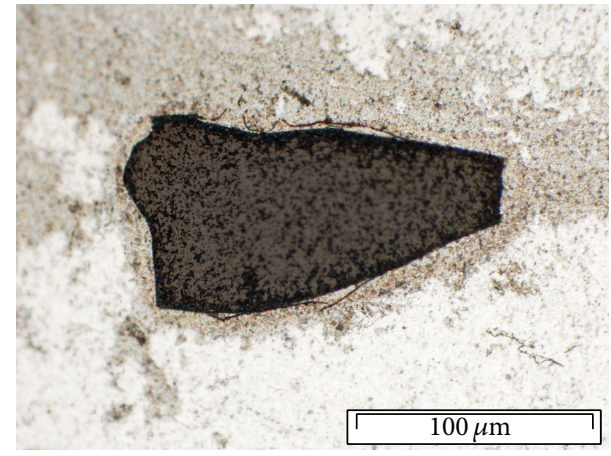

(b)

FIGURE 5: LM micrographs of pressure die cast composite, polished cross section unetched, and continuous GCp-matrix bonding are visible.

the cast iron counter were measured prior to and after each test, with the precision of $0.0001 \mathrm{~g}$. Examinations of the composite surface after the sliding friction test were performed with a SEM Hitachi S4200 equipped with an energy dispersive spectrometer (EDS). A comparison of the wear track topography depending on the applied Mg3Al-GCp composite technology was carried out by means of optical MicroProf (CWL3000) produced by FRT [7].

\section{Results and Discussion}

3.1. Microstructure. Examples of the microstructure observations of the Mg3Al-GCp composite obtained by the two casting procedures are presented in Figures 3-6. The distribution of the particles is proper, and the latter do not form clusters independently of the applied technology. Yet, in the case of the gravity cast material, microvoids between the particles 


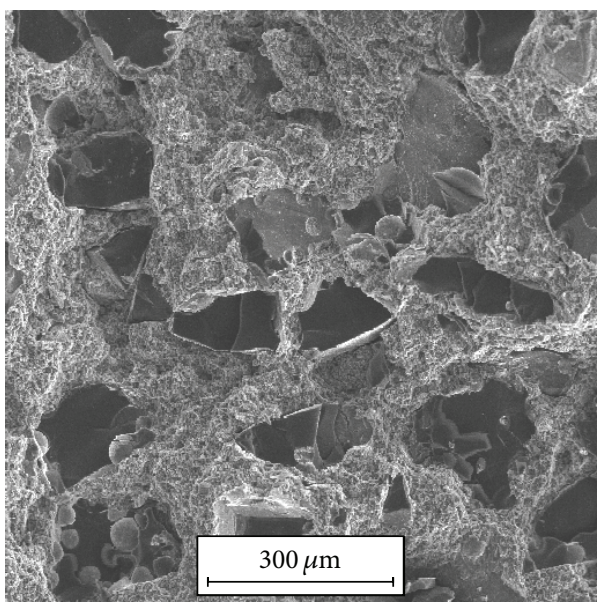

(a)

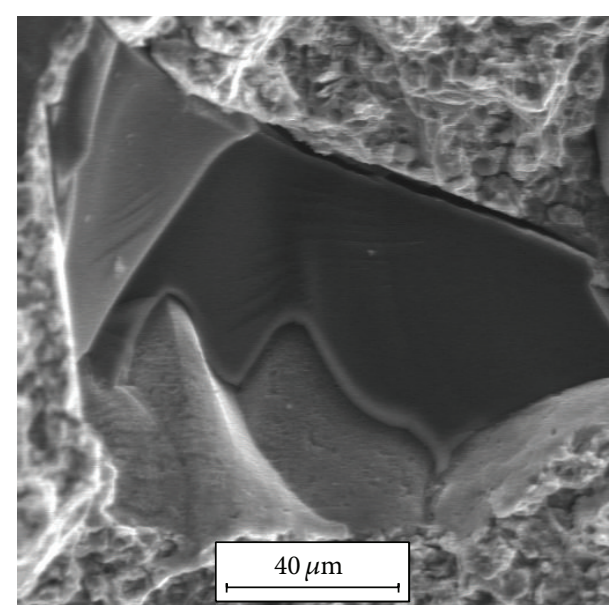

(b)

FIGURE 6: SEM micrographs of pressure die cast composite (fractured cross section), particles well bonded with matrix, and decohesion of particles and microvoids at particle-matrix boundary are visible.

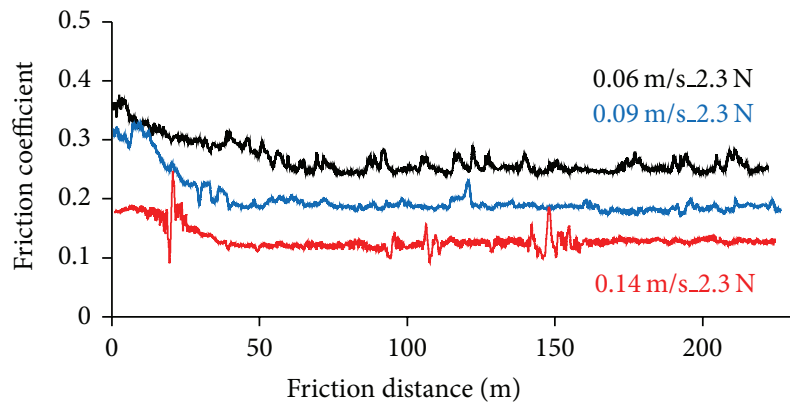

(a)

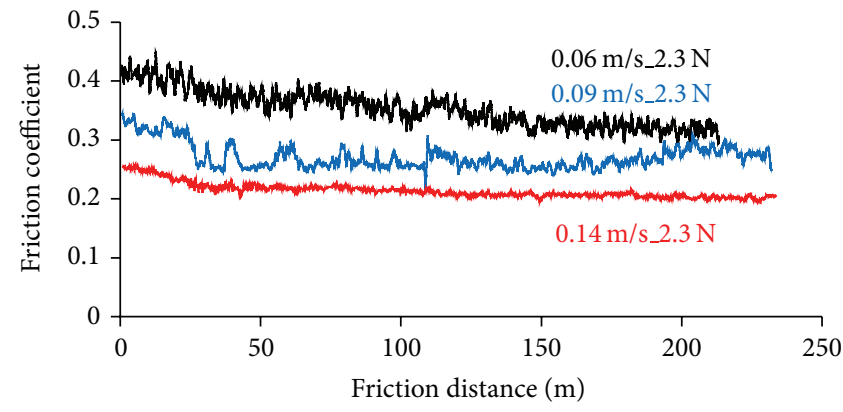

(b)

FIGURE 7: Changes in friction coefficient with sliding distance for load of $2.3 \mathrm{~N}$ and different speeds: (a) gravity cast composite and (b) pressure die cast composite.

and the matrix are locally registered in the polished samples (Figure 3), which suggests weak bonding. This is confirmed by the images of the composite's surface after the decohesion in the tensile strength test (Figure 4), where the effect of the GCp's pulling out is visible and also microvoids, both at the interface and in the matrix, are observed. The results of the pressure die cast composite's examination by LM did not reveal any discontinuity of the metal-GCp bonding (Figure 5). On the fractured surface (Figure 6), GCp, both destroyed and well bonded with the matrix, were visible, which suggests that the particles actively participated in the decohesion process of the composite. Moreover, the microstructure of the deformed metal matrix was finer than that in the case of the gravity cast composite, which was a result of the different metal crystallization conditions. The results of the microstructure observations clearly explain why the mechanical properties of the pressure die cast composite are considerably higher.

3.2. Tribological Tests. The curves of the friction coefficient $(\mu)$ versus the sliding distance, the mean friction coefficient, and the mass loss measured at the applied experiment conditions for the gravity cast and pressure die cast composite are presented in Figures 7, 8, 9, 10, and 11, respectively. The analysis of the friction curves character (Figures 7-9) showed that, in the case of the pressure die cast material, the changes of the $\mu$ value are generally less sharp.

The mean friction coefficient (Figure 10) at the measured distance decreased with the friction speed for the same load, independently of the material casting procedure. Moreover, in the case of the pressure die cast composite, the value of $\mu$ for the same friction speed decreased with the load increase, while for the gravity cast material, no tendency for changes was observed. The comparison of the $\mu$ mean value for both materials revealed that the value was higher or similar for the pressure die cast composite and particularly low for the load of $9.3 \mathrm{~N}$ and the speed of $0.14 \mathrm{~m} / \mathrm{s}(\mu=0.13)$.

The measurements of the mass loss (Figure 11) showed that the changes of the cast iron counter's mass were at the level of the measurement accuracy, while in the case of the composite, differences dependent on the applied material technology were observed. Generally, the mass loss increased with the load, yet it was evidently lower for the pressure die 


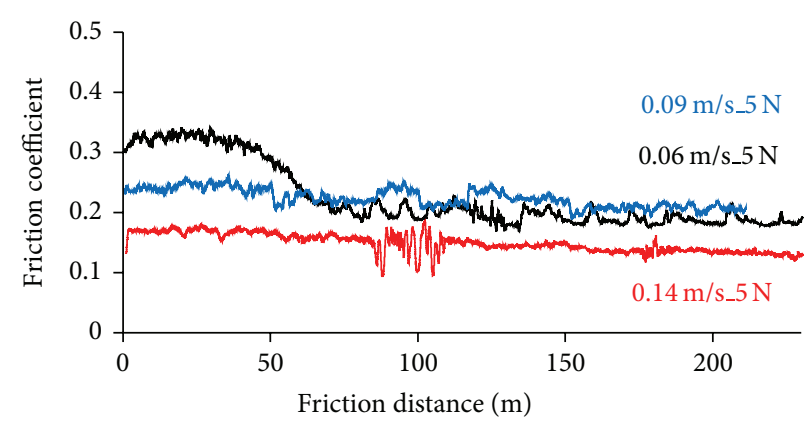

(a)

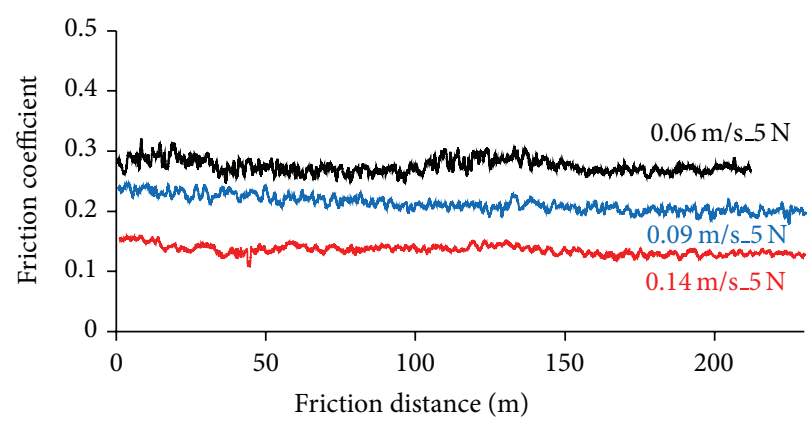

(b)

FIGURE 8: Changes in friction coefficient with sliding distance for load of $5 \mathrm{~N}$ and different speeds: (a) gravity cast composite and (b) pressure die cast composite.

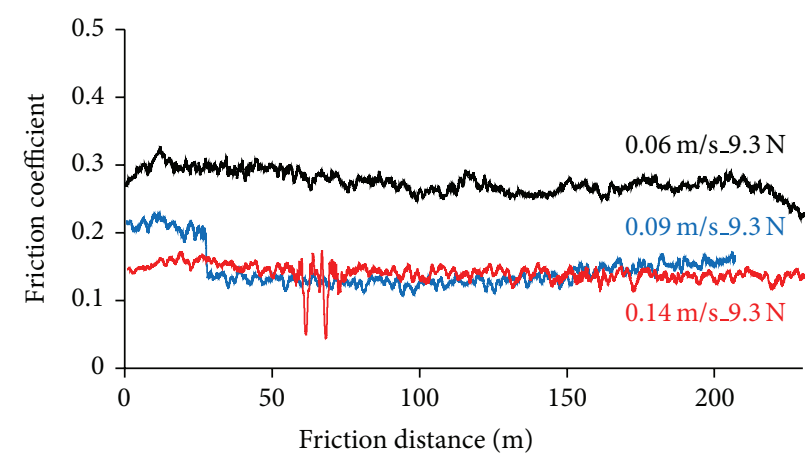

(a)

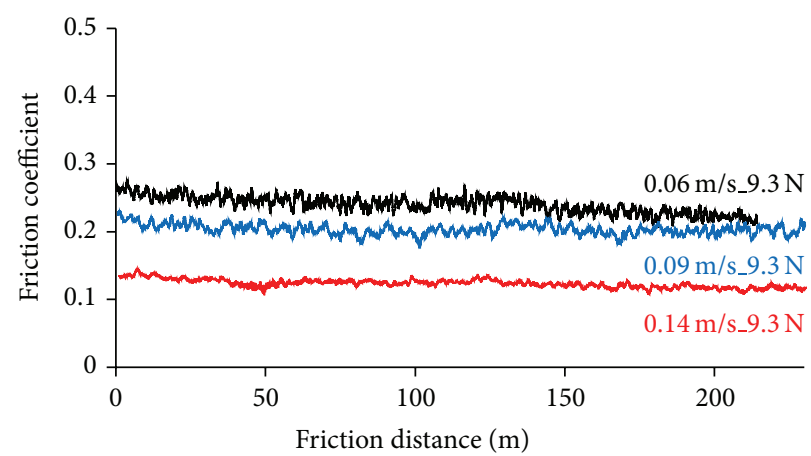

(b)

FIGURE 9: Changes in friction coefficient with sliding distance for load of $9.3 \mathrm{~N}$ and different speeds: (a) gravity cast composite and (b) pressure die cast composite.

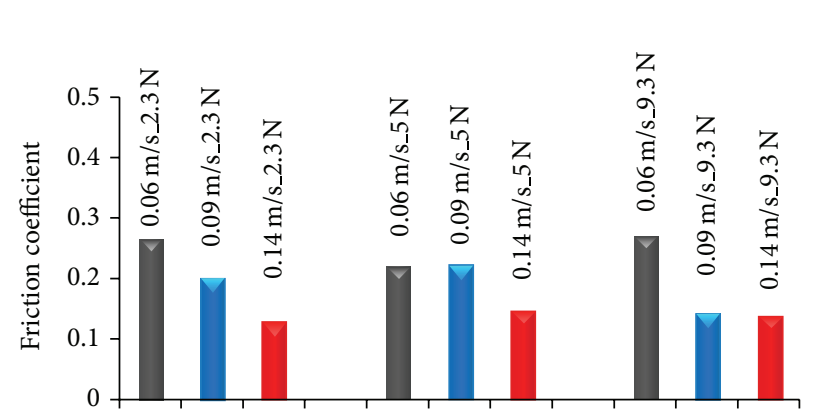

(a)

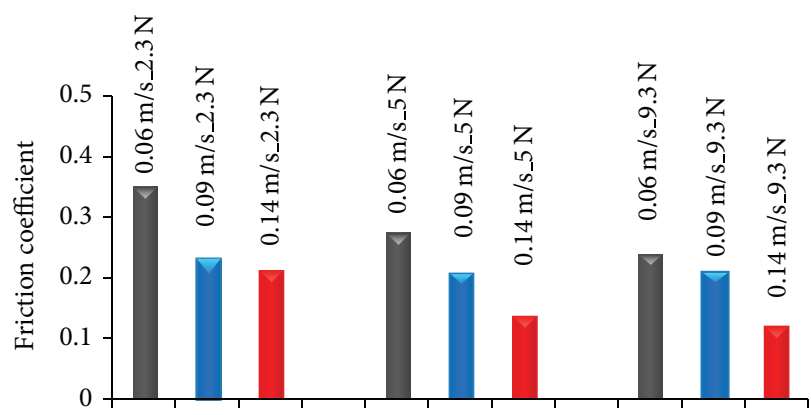

(b)

FIGURE 10: Mean friction coefficient determined for different parameters for (a) gravity cast composite and (b) pressure die cast composite.

cast material, which suggests the occurrence of different wear mechanisms.

This was confirmed by the SEM (secondary electron technique, SE) with energy dispersive spectrometry (EDS) investigations (Figures 12-15) of the worn surface, formed at the same sliding friction conditions $(9.3 \mathrm{~N}, 0.14 \mathrm{~m} / \mathrm{s})$. In the gravity cast composite, one could observe a more intense degradation of the particles by microfragmentation and their local delamination from the matrix (Figure 12), as well as an accumulation of oxides both around the GCp and in the wear grooves which were formed in the magnesium matrix
(Figure 13). The very high intensity of the oxide agglomerate formation was a result of the presence of micropores in the initial material. This caused microsized fragments being pulled out of the magnesium matrix, which were oxidized in situ or later. In the case of the pressure die cast composite, the oxides were located similarly (Figures 14 and 15) but they were finer and registered with a less frequency. Because of the strong bonding between the components, the dominant wear effect visible on the worn surface was the groove formation in the matrix and the microvoids on the GCp surface, which were oriented parallel or perpendicular to the counter 


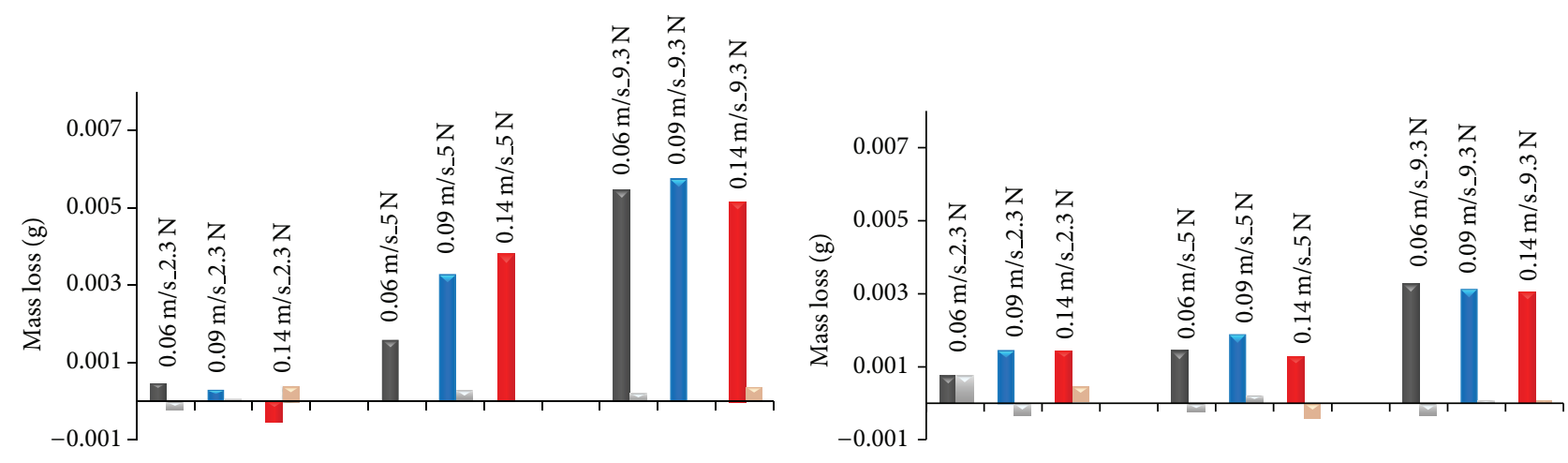

(a)

(b)

FIGURE 11: Mass loss of a sample and a cast iron counter measured after tests for different parameters: (a) gravity cast composite and (b) pressure die cast composite.
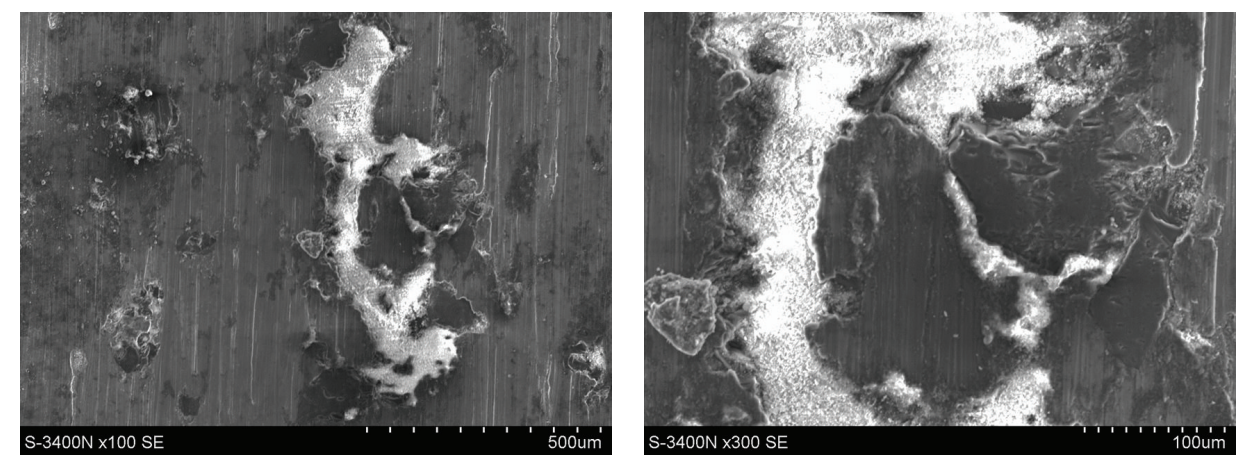

FIGURE 12: SEM micrographs of a Mg3Al-GCp gravity cast composite surface, after sliding friction test (load $9.3 \mathrm{~N}$, speed $0.14 \mathrm{~m} / \mathrm{s}$ ).
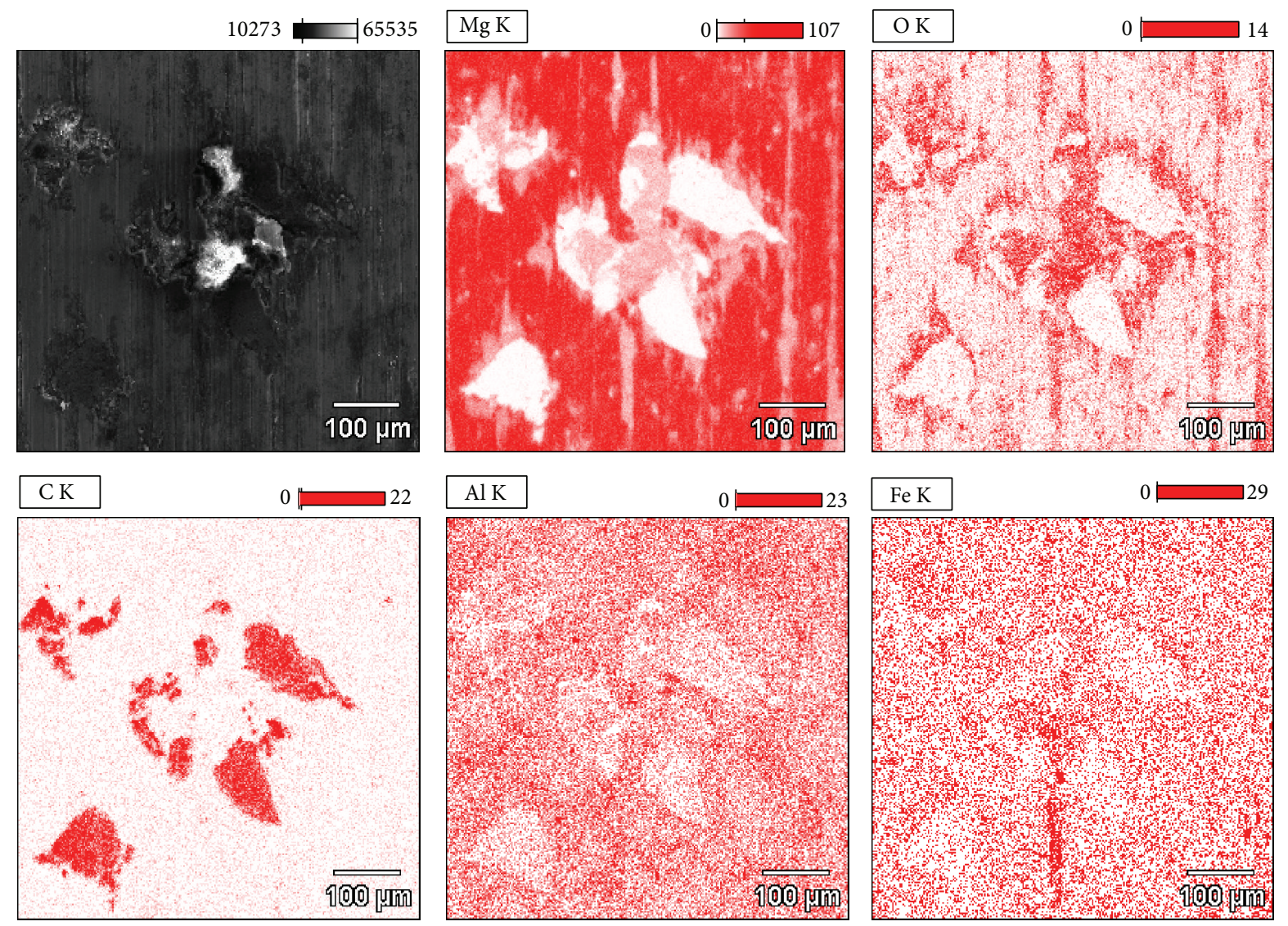

FIGURE 13: SE image and Mg, O, C, Al, Fe X-ray maps of a Mg3Al-GCp gravity cast composite surface, after sliding friction test (load 9.3 N, speed $0.14 \mathrm{~m} / \mathrm{s}$ ). 

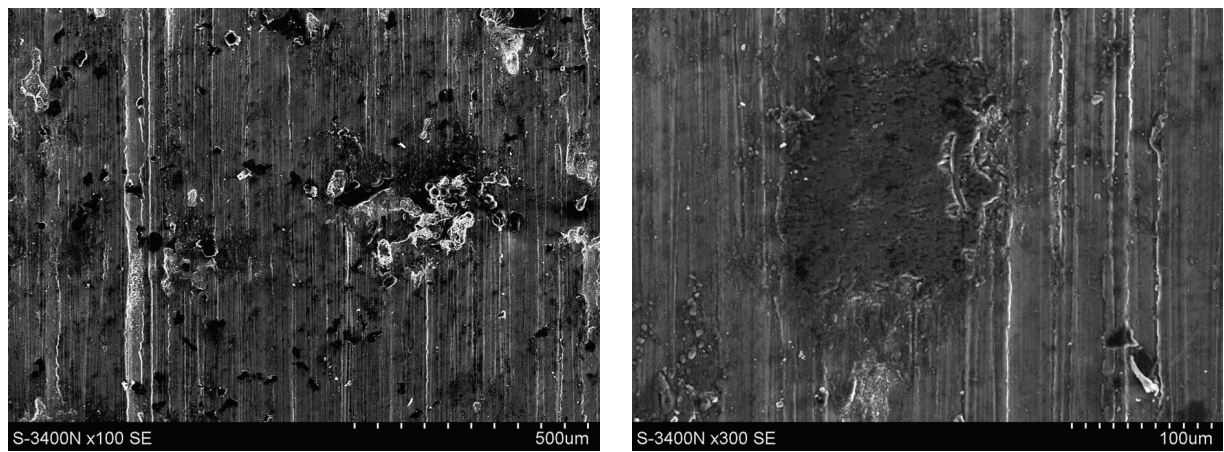

FIGURE 14: SEM micrographs of a Mg3Al-GCp pressure die cast composite surface, after sliding friction test (load $9.3 \mathrm{~N}$, speed $0.14 \mathrm{~m} / \mathrm{s}$ ).
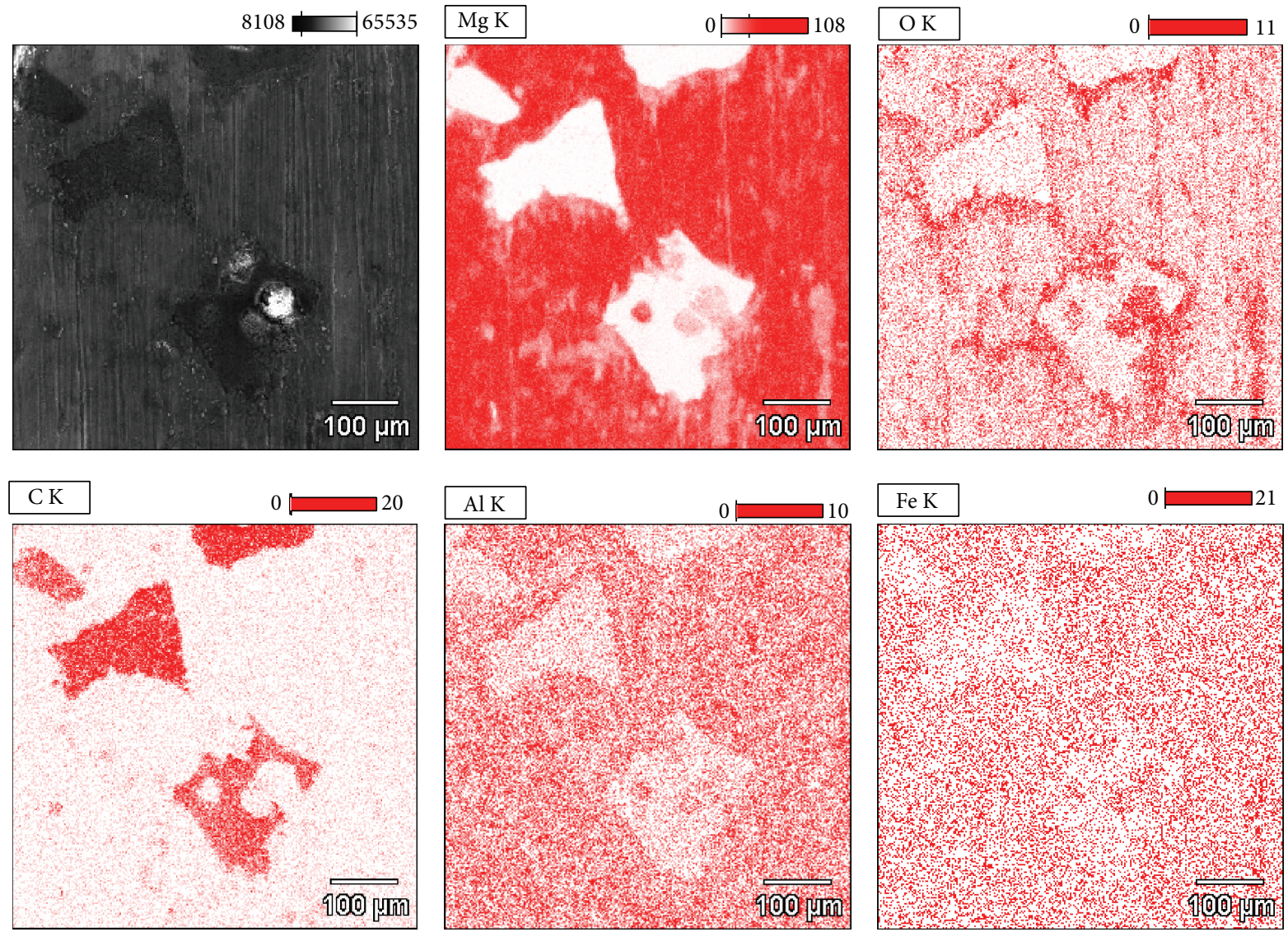

Figure 15: SE image and Mg, O, C, Al, Fe X-ray maps of a Mg3Al-GCp pressure die cast composite surface, after sliding friction test (load $9.3 \mathrm{~N}$, speed $0.14 \mathrm{~m} / \mathrm{s}$ ).

movement, respectively. This explains the lower mass loss of the pressure die cast composite.

In spite of the worse wear resistance and mechanical properties of the gravity cast composite, its friction coefficient value was lower or similar for lower loads and sliding speeds, in comparison with the pressure die cast one. This was a result of the presence of a lubricant which was forming between the Mg3Al-GCp composite and the cast iron counter, independently of the material technology. In addition to the oxide and metal molecules, the wear product contains very fine glassy carbon, generated owing to the low shear resistance of GCp, which improves the conditions of the sliding friction $[3,5]$.

The increase of the wear resistance due to the application of pressure die casting was verified by the wear tracks topography analysis (Figure 16). The depth of a track formed after the sliding friction for the load of $9.3 \mathrm{~N}$ and the speed of $0.14 \mathrm{~m} / \mathrm{s}$ was clearly higher for the gravity cast material. That effect was mainly a result of the revealed higher mass loss 


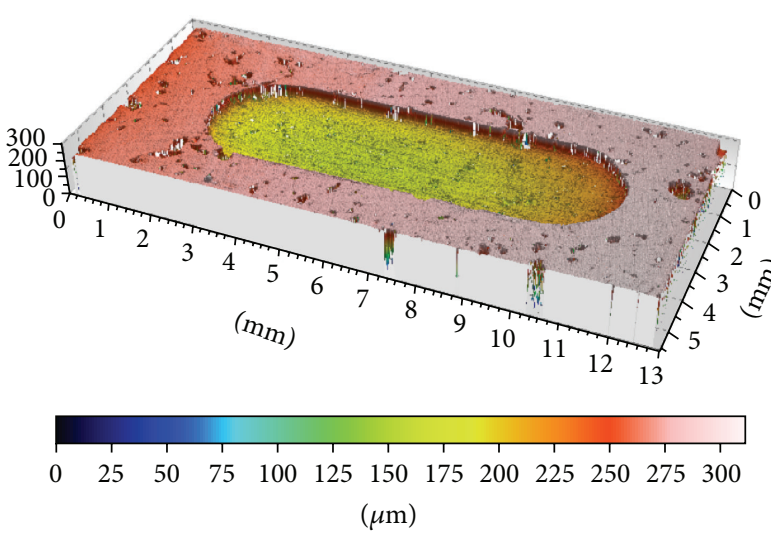

(a)

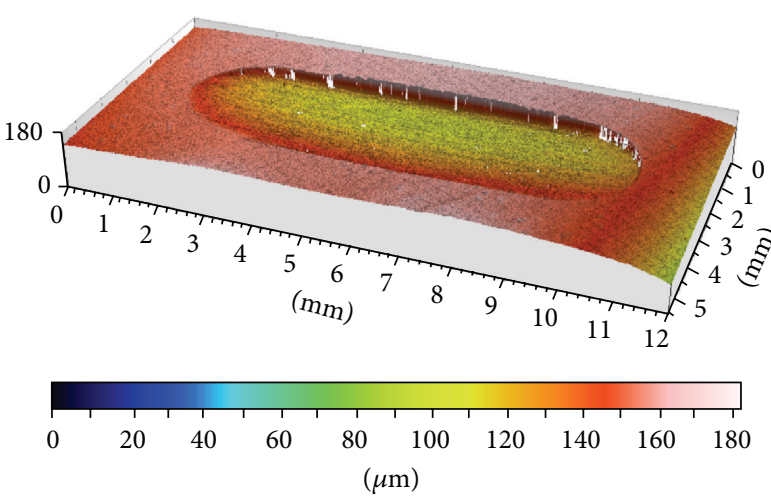

(b)

FIGURE 16: 3D images of a wear track topography formed in a Mg3Al-GCp gravity cast (a) and pressure die cast (b) composite after sliding friction tests (load $9.3 \mathrm{~N}$, speed $0.14 \mathrm{~m} / \mathrm{s}$ ).

and also of the closing of the micropores in the gravity cast composite, caused by the loaded iron cast counter interaction, which influenced the increase of the wear track depth.

\section{Conclusions}

On the basis of the comparison of the microstructure and tribological properties of the Mg3Al-GCp composite, obtained from a suspension of the same composition and temperature but by means of two different casting procedures, that is, gravity casting and pressure die casting, one can draw the following conclusions.

(i) The pressure die casting technology eliminates the micropores at the matrix-GCp interface and in the matrix and ensures better mechanical properties of the composite.

(ii) At the applied conditions, the mean friction coefficient of both investigated materials is similar or slightly higher for the pressure die cast composite, but, in the case of that material, its value during the sliding friction is more stable.

(iii) The obtained composite under some sliding friction conditions is characterized by a particularly low friction coefficient-at the level of 0.13 .

(iv) For the loads of 5 and $9.3 \mathrm{~N}$, the wear resistance of the pressure die cast composite is evidently higher than that of the gravity cast one. This is confirmed by the mass loss as well as the wear tracks depth measurements.

(v) The differences in the wear intensity dependent on the technology are associated with the wear mechanism. In the gravity cast composite, where the mass loss is higher, one can observe GCp being pulled out or fragmented, as a consequence of the weak bonding with the matrix, while in the pressure die cast composite one can mainly register microvoids on the GCp surface.

\section{Conflict of Interests}

The authors declare that there is no conflict of interests regarding the publication of this paper.

\section{Acknowledgment}

This work was supported by the Ministry of Science and Higher Education of Poland (Project N Nr 15-0077-10/2010).

\section{References}

[1] O. J. A. Schueller, S. T. Brittain, C. Marzolin, and G. M. Whitesides, "Fabrication and characterization of glassy carbon MEMS," Chemistry of Materials, vol. 9, no. 6, pp. 1399-1406, 1997.

[2] N. L. Pocard, D. C. Alsmeyer, R. L. McCreery, T. X. Neenan, and M. R. Callstrom, "Doped glassy carbon: a new material for electrocatalysis," Journal of Materials Chemistry, vol. 2, no. 8, pp. 771-784, 1992.

[3] A. Posmyk and J. Myalski, "Producing of composite materials with aluminium alloy matrix containing solid lubricants," Diffusion and Defect Data Pt.B: Solid State Phenomena, vol. 191, pp. 67-74, 2012.

[4] B. Juszczyk, J. Kulasa, W. Malec, S. Malara, M. Czepelak, and L. Ciura, "Microstructure and tribological properties of the copper matrix composite materials containing lubricating phase particles," Archives of Metallurgy and Materials, vol. 59, no. 1, pp. 365-369, 2014.

[5] A. Olszówka-Myalska, J. Myalski, and K. Wrzała, "Fabrication of magnesium matrix composite with glassy carbon particles by pressure die casting," Composites Theory and Practice, vol. 14, no. 2, pp. 101-105, 2014.

[6] A. Olszówka-Myalska, J. Myalski, and A. Botor-Probierz, "Effect of glassy carbon particles on wear resistance of AZ91E matrix composite," Diffusion and Defect Data Pt.B: Solid State Phenomena, vol. 176, pp. 127-138, 2011.

[7] J. Przondziono, W. Walke, A. Szuła, E. Hadasik, J. Szala, and J. Wieczorek, "Resistance to corrosion of magnesium alloy AZ31 after plastic working," Metalurgija, vol. 50, no. 4, pp. 239-243, 2011. 

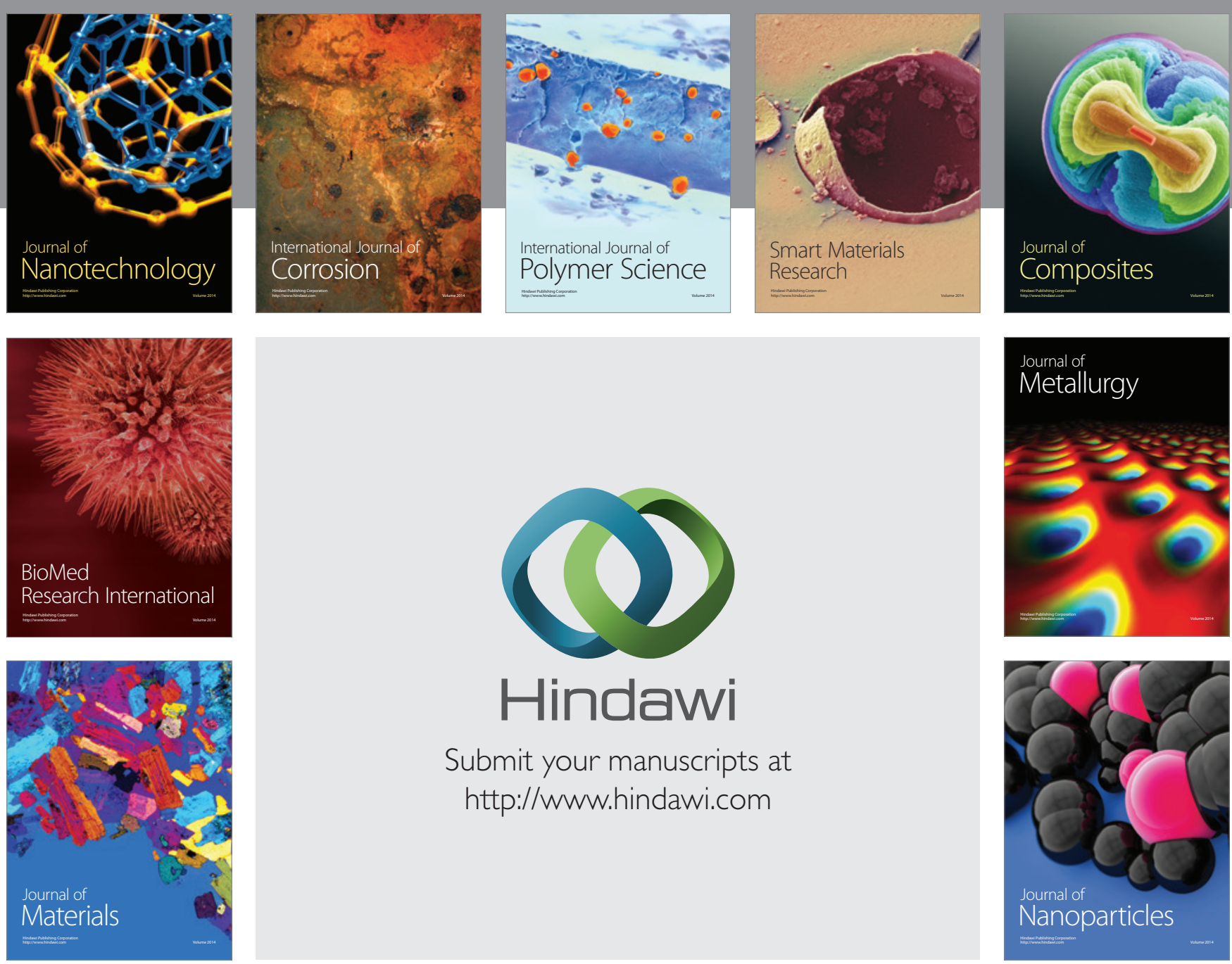

Submit your manuscripts at http://www.hindawi.com
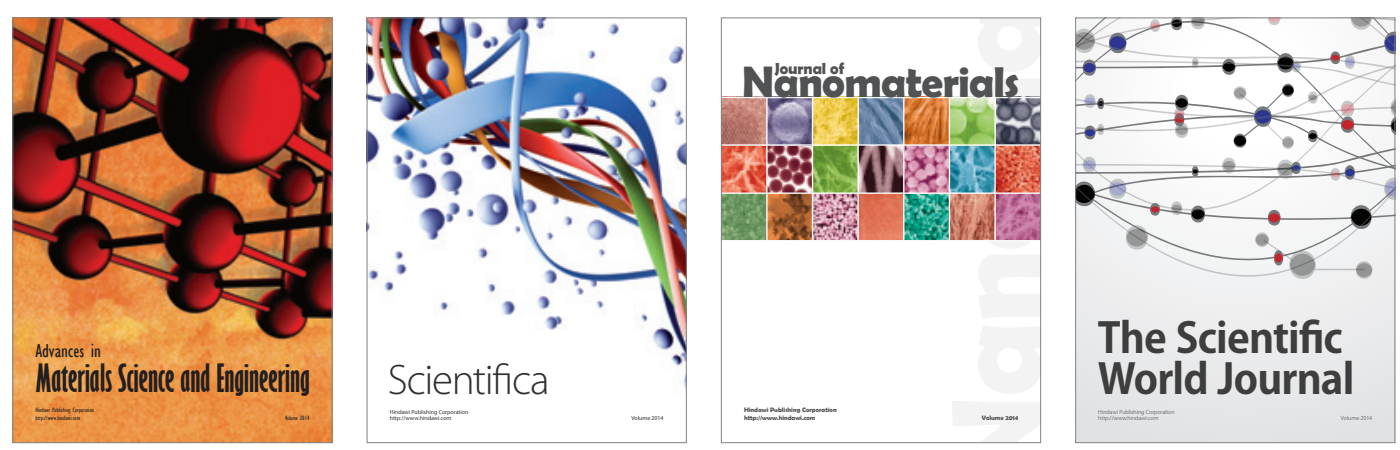

\section{The Scientific World Journal}
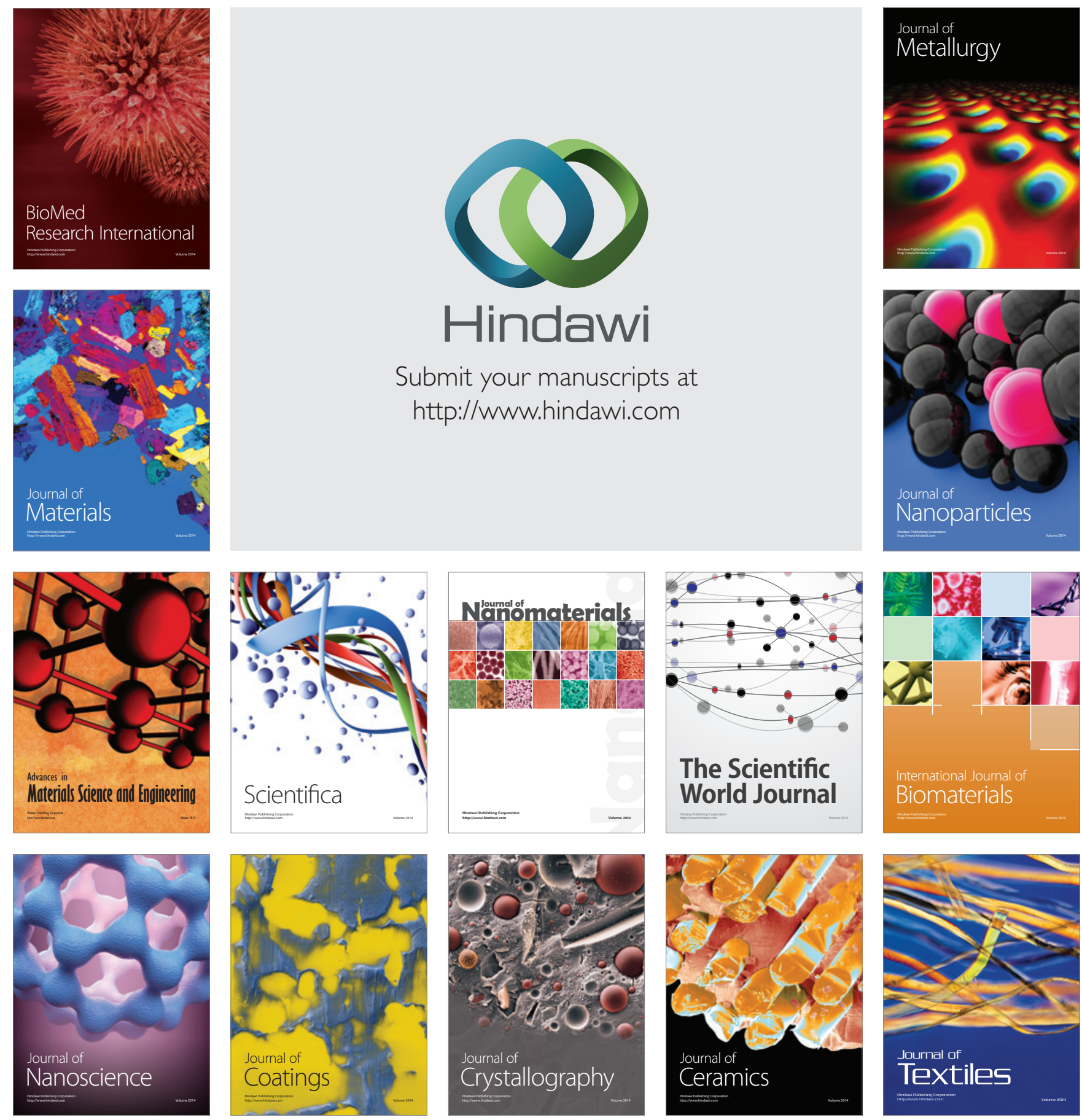